\title{
POLÍTICA PARA A CIÊNCIA E POLÍTICA DA CIÊNCIA: ENTRE O FOMENTO E AS DEMANDAS GOVERNAMENTAIS
}

\author{
ROGÉRIO BEZERRA SILVA*
}

\begin{abstract}
RESUMO: O artigo analisa o debate sobre a relação universidade-governo nos países avançados no que diz respeito à produção de conhecimento científico (pesquisa científica). Para isso, ele se apoia, principalmente, nos estudos de autores franceses e estadunidenses. Essa relação é analisada segundo duas dimensões: a da política da ciência, em que a universidade tem suas autonomias de gestão e de pesquisa reduzidas, ou mesmo suprimidas, pelo governo; e a da política para a ciência, em que a universidade tem suas autonomias de gestão e de pesquisa preservadas. Essas dimensões permitem a identificação de quatro categorias de relacionamento entre universidade e governo: universidade associada ou subordinada ao governo, na primeira dimensão; e universidade independente ou tributária do governo, na segunda. Essas categorias ajudam a mostrar que a universidade, longe de responder a uma concepção única sobre a organização de sua pesquisa e de sua gestão, é formada desde relações de poder existentes em cada momento histórico.
\end{abstract}

Palavras-chave: Universidade. Governo. Produção de conhecimento científico.

\section{POLICY FOR SCIENCE AND SCIENCE POLICY: BETWEEN THE GOVERNMENT FOMENTATION AND DEMANDS}

ABSTRACT: The article analyzes the debate on the relationship between universities and government in advanced countries with regard to the production of scientific knowledge (research). Thereupon this article was primarily supported in studies of French and American authors. This relationship is analyzed along two dimensions: the science policy, where the university has its independent management and academic freedom reduced, or even eliminated, by the government; and the policy for science, where the university has its independent management and academic freedom preserved. These dimensions allow the identification of four categories of relationship between government and university: university associate or subordinate to the government, in the first dimension; and independent or tributary to the

* Doutorando em Política Científica e Tecnológica na Universidade Estadual de Campinas (Unicamp) e pesquisador do Grupo de Análise de Políticas de Inovação (Gapi) da mesma Instituição. E-mail: rogerio.silva@ige.unicamp.br 
government, on second. These categories contribute to show that the university, far from responding to a single conception of the organization of its independent management and academic freedom, is constituted by existing power relations in each historical moment.

Key words: University. Government. Production of scientific knowledge.

\title{
POLITIQUE POUR LA SCIENCE ET POLITIQUE DE LA SCIENCE: ENTRE PROMOTION ET EXIGENCES GOUVERNEMENTALES
}

\begin{abstract}
RÉSUMÉ: L'article analyse le débat sur la relation université-gouvernement dans les pays avancés sur le plan de la production de la connaîssance scientifique (recherche scientifique). Pour cela, il s'appuie principalement sur les études d'auteurs français et américains. Cette relation est analysée selon deux dimensions: celle de la politique de la science, où l'université voit ses autonomies de gestion et de recherche réduites, ou même supprimées, par le gouvernement; et celle de la politique pour la science, où l'université a ses autonomies de gestion et de recherche préservées. Ces dimensions permettent l'identification de quatre catégories de relation entre université et gouvernement: université associée ou subordonnée au gouvernement, dans la première dimension; et université indépendante ou sous-contrat de l'Etat, dans la seconde. Ces catégories aident à montrer que l'université, loin de répondre à une conception unique sur l'organisation de sa recherche et de sa gestion, est formée de relations de pouvoir existentes à chaque moment historique.
\end{abstract}

Mots-clés: Université. Gouvernement. Production de connaîssance scientifique.

\section{Introdução}

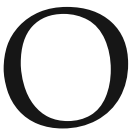

artigo analisa o debate sobre a relação entre a universidade e o governo nos países de capitalismo avançado (países avançados), especialmente na Europa e nos EUA, no que diz respeito ao processo de produção de conhecimento científico (pesquisa científica, daqui em diante). Com essa análise espera-se fornecer subsídios ao debate acerca dessa relação nos países de capitalismo periférico (países periféricos), sobretudo no Brasil.

Para dar conta de seu objetivo, o artigo se apoia principalmente nas obras de autores franceses e estadunidenses dedicadas à compreensão das transformações ocorridas na universidade de seus países, desde o final da Segunda Guerra Mundial pelo menos, e na pesquisa científica por ela produzida.

A relação da universidade com a sociedade (a relação da universidade como o governo, movimentos sociais, empresas etc.) se tornou um dos mais controvertidos debates da contemporaneidade. É marcante nele a percepção de que a sociedade vem, desde a década de 1960, principalmente, pressionando a universidade a se tornar mais aderente às suas demandas cognitivas (demandas por conhecimento científico, ou demandas por pesquisa). 
Contudo, mesmo diante dessa pressão, não é tarefa fácil influenciar a universidade, pois a sua principal luta é pela ampliação de suas autonomias de gestão (independent management) e de pesquisa (academic freedom).

Só mais recentemente, sobretudo desde os anos de 1980, é que começou a ganhar força entre membros da comunidade de pesquisa (professores-pesquisadores, inclusive os temporariamente licenciados do cargo para ocupar alguma função no governo, e aqueles profissionais dedicados somente à pesquisa) dos países avançados, e também dos periféricos, a ideia de que a universidade deve se tornar mais aderente às demandas da sociedade por pesquisa.

Para esses membros da comunidade de pesquisa, é não somente aceitável, como também desejável direcionar a pesquisa ao atendimento dessas demandas e, além do governo, legitimar outras instituições sociais, especialmente a empresa, como alocadoras de recursos nas atividades da universidade para torná-la autônoma financeiramente (autonomy). Para eles, a demanda da sociedade por pesquisa (por conhecimento científico) é reduzida à exercida pela empresa e pelo governo. Neste caso, sociedade passa a significar empresa e governo.

Permitir ou não que outras instituições sociais aloquem recursos na pesquisa pela universidade produzida? Longe de um debate dicotômico, quando se analisa o comportamento da comunidade de pesquisa dos países avançados, são encontrados limites tênues entre aqueles que defendem uma maior aproximação da universidade com outras instituições e aqueles que são contrários.

E o governo, como se apresenta no debate? Essa pergunta é fundamental, pois ele (tanto nos países avançados como nos periféricos), desde a Primeira Guerra Mundial, pelo menos, se tornou o principal alocador de recursos na pesquisa produzida pela universidade.

O trabalho, além desta introdução, possui outras quatro seções. A seção 1 apresenta o controvertido debate acerca da relação universidade-sociedade, em especial com o governo e com a empresa, nos países avançados de fins da Segunda Guerra Mundial até a atualidade.

A seção 2 apresenta duas dimensões de atuação do governo em relação à universidade: a da política para a ciência e a da política da ciência. A seção 3 apresenta quatro categorias de relacionamento, derivadas dessas duas dimensões, entre governo e universidade. E, por fim, a seção 4 apresenta as considerações finais.

As quatro categorias de relacionamento apresentadas ajudam a mostrar que a universidade, longe de responder a uma concepção única sobre a organização de sua pesquisa, é formada desde relações de poder existentes em cada momento histórico. 


\section{Controle vs. autonomias}

O período pós-Segunda Guerra Mundial teve como uma de suas características o esforço de governos e de comunidades de pesquisa dos países avançados em colocar a pesquisa científica a serviço de suas nações. Para eles, a pesquisa, se suficientemente apoiada pelo governo, seria decisiva na resolução de problemas econômicos e sociais. Mais ainda, o Estado e a sociedade deveriam ser orientados pelos princípios e normas da racionalidade científica (SCHWARTZMAN, 1998).

Esse apoio à pesquisa começou a se configurar no contexto da publicação do relatório Science: the endless frontier (conhecido no Brasil como Relatório Busch) em 1945, elaborado por Vannevar Bush, então diretor do Office of Scientific Research and Development, que foi solicitado pelo presidente dos EUA, Franklin D. Roosevelt, mas entregue ao seu sucessor, Herry Truman (DIAS, 2005).

Na prática, o Relatório destacava a necessidade do apoio governamental à pesquisa depois do término da Segunda Guerra. Ele buscava, em tempos de paz, garantir à pesquisa a mesma atenção recebida durante a guerra (idem, ibid.).

O Relatório Bush, todavia, não trazia nenhum elemento essencialmente novo ao debate sobre a pesquisa científica produzida e o apoio governamental a ela. Ele apenas sintetizava, no período em que foi elaborado, o sentimento comum à comunidade de pesquisa e a alguns policy makers (fazedores de política) a respeito da importância da pesquisa científica para o progresso econômico. Sentimento manifestado já durante a Primeira Guerra Mundial e na preocupação dos norte-americanos de que os europeus pudessem adquirir competência científica e tecnológica superior as suas (idem, ibid.).

De fato, atendendo ao receituário do Relatório, governantes dos países avançados multiplicaram os recursos destinados à pesquisa e, com isso, ampliaram a qualidade e a quantidade de membros da comunidade pesquisa, de laboratórios e de instituições de ensino superior (idem, ibid.).

Até aproximadamente o final da Segunda Guerra, o prestígio da comunidade de pesquisa não podia ser comparado, salvo exceções, ao dos militares, dos políticos ou dos empresários (KOURGANOFF, 1990).

O apoio à pesquisa pós-Segunda Guerra fez com que a comunidade de pesquisa se tornasse muito prestigiada socialmente em decorrência das aplicações (no âmbito da energia nuclear, da medicina ou das teletransmissões, por exemplo) de pesquisas que, em princípio, não transpareciam à sociedade terem um fim utilitário. Isso fez a sociedade (especialmente o governo) crer num valor imediato ou potencial da pesquisa científica como fonte de poder político ou econômico (idem, ibid.). 
Contudo, como defendia a comunidade de pesquisa, somente se concedidas à universidade autonomias de gestão (independent management) - sobre as decisões acerca de sua administração - e de pesquisa (academic freedom) - sobre as decisões acerca dos problemas (ou temas) a serem pesquisados e dos métodos empregados - é que a sociedade encontraria um fim utilitário para a pesquisa.

Já na década de 1960, todavia, europeus e norte-americanos iniciaram um grande movimento de descrença da universidade (idem, ibid.). Estudantes, ministros, jornalistas, pais e empresários não se cansavam de criticá-la publicamente. Acusavam-na de ter se tornado altamente dispendiosa e que, ao contrário do ocorrido duas décadas antes, estava logrando poucos benefícios para a sociedade.

Engrossou-se então o "caldo da discussão" no âmbito social acerca da missão da universidade. Aos olhos dos estudantes e de suas famílias, a missão da universidade era a de transformá-los em médicos, juristas, engenheiros, professores etc. E para os empresários, ela devia fornecer a mão de obra necessária aos setores da economia nacional. Ou seja, os anseios de ambos em relação à universidade convergiam (KOURGANOFF, op. cit.).

E o que ansiava a universidade? Nela, havia professores-pesquisadores que acreditavam que sua missão era menos a de formar homens que a de enriquecer permanentemente o patrimônio cultural. Para outros, todavia, sua missão era econômica e, por isso, deviam formar mão de obra, tão competente quanto possível, para os setores produtivos (idem, ibid.). Dentro dela, as opiniões eram mais divergentes do que se observava de fora.

Nas décadas de 1960 e 1970, as autonomias que a universidade havia conquistado até então, frente às diversas instituições sociais, principalmente frente ao governo, estavam fortemente ameaçadas (BOURDIEU, 2003).

É devido, talvez, a essa ameaça que a universidade tenha buscado incorporar as demandas cognitivas da sociedade as suas pesquisas. Pelo menos foi esse um discurso adotado pela comunidade de pesquisa.

$\mathrm{Na}$ medida em que a sociedade buscava agir sobre a pesquisa da universidade, o governo a pressionava a se tornar autônoma financeiramente (autonomy). Ou seja, pressionava a universidade a buscar outras fontes de recursos que não as governamentais.

Porém, diferente das outras duas (das autonomias de gestão e de pesquisa), a autonomia financeira não era aceita por boa parte da comunidade de pesquisa. Não era por ela que vinham lutando havia décadas. Por isso, membros da comunidade de pesquisa passaram a dizer que o dever deles era o de sempre reivindicar melhorias julgadas indispensáveis à universidade. 
A partir dessas décadas, um argumento passou a ser ainda mais utilizado pela comunidade de pesquisa, a fim de impedir o enxugamento de suas fontes de recursos: o objetivo primordial da pesquisa não era mais o de promover descobertas, então consideradas pela sociedade como aleatórias e de rentabilidade incerta, mas o de "formar homens com espírito de pesquisadores" (KOURGANOFF, 1990, p. 31).

Foi no contexto de pressão social sobre as autonomias da universidade que tomou consistência aquele que veio a se tornar o mais controvertido debate acadêmico: a abertura da pesquisa da universidade às demandas cognitivas da sociedade.

No entanto, diferente do que muitos imaginam, alguns dos principais enfoques que tratam sobre a vinculação da universidade com a sociedade não necessariamente defendem sua autonomia financeira em relação ao governo. Muito pelo contrário, eles até reforçam a necessidade do apoio financeiro do governo à conformação de arranjos institucionais voltados à pesquisa científica. Essas abordagens também reduzem a sociedade ao governo e à empresa. Ou seja, o governo e a empresa representam, para esses enfoques, todas as demandas da sociedade por pesquisa científica.

Dentre as várias abordagens sobre as transformações recentes da pesquisa produzida pela universidade dos países avançados, cabe destacar os da New Production of Knowledge (NPC), o da Triple Helix (TH) e o da Economia da Inovação (EI).

Nesses enfoques três instituições sociais são fundamentais: a universidade, o governo e a empresa. Cada uma dessas instituições possui funções distintas na dinâmica de pesquisa. Veja-se o que dizem sobre a universidade e o governo, que é a relação que se quer explorar aqui.

Sobre a universidade, diz o enfoque da EI, os avanços científicos registrados ao longo do século XX levam-na a tratar de forma mais objetiva sua missão de investigadora, permitindo com que oriente parte de suas atividades à pesquisa para as empresas. A universidade se converte não somente em uma instituição social capaz de dar soluções a problemas teóricos e abstratos, mas também de resolver problemas específicos e aplicados (RUIZ, 2005).

Para a NPC, à medida que as "novas formas de produção de conhecimento" são difundidas, deixam mais porosas as velhas fronteiras entre "pesquisa básica" e "pesquisa aplicada". A universidade também adota "valores" da cultura empresarial, dando lugar assim a um tipo completamente novo de empresário, o acadêmico (GIBBONS et al., 1994).

Para a TH, a universidade deve ser empreendedora. Cabe a ela, por um lado, despertar nos alunos sua criatividade, liderança e visão de futuro voltada à inovação, 
para que, com isso, possam ocupar seu espaço no mercado, e, por outro lado, apoiar a comunidade de pesquisa a criar suas próprias empresas de "alta tecnologia" (ETZKOWITZ, 2002).

O governo, para a EI, por meio da elaboração de políticas públicas, pode ajudar a universidade a "se desprender do passado" e a adotar outras trajetórias de desenvolvimento. O governo deve alocar recursos em pesquisas voltadas à exploração econômica, consistente com os interesses das múltiplas instituições sociais (CIMOLI et al., 2007).

Para a NPC, a aparição de um "novo modo de produzir conhecimento" está criando "novos" desafios para o governo. A descentralização da universidade a torna mais permeável às demandas sociais, o que leva à ampliação da competitividade dos sistemas de inovação nacionais (GIBBONS et al., 1994).

Para a TH, o governo deve instituir políticas voltadas à vinculação universidade-empresa, pois elas estimulam a interação dessas instituições e, como resultado disso, novas ideias podem surgir e gerar inovações (ETZKOWITZ, 2002).

Embora haja algumas distinções entre os três enfoques, eles destacam o governo como tendo a função de regular ou facilitar as relações entre a universidade e a empresa. Por meio da atuação do governo, a universidade pode se rearranjar de forma mais conveniente com a empresa para produzir pesquisas que atendam as suas demandas.

Parcela da comunidade de pesquisa também acredita que a autonomia financeira é positiva, pois ela leva a universidade a diversificar suas fontes de recursos. Isso contribui para o fortalecimento da capacidade administrativa da universidade, para a criação de programas de pesquisa não departamentais e de pesquisas conectadas aos interesses das instituições econômicas (CLARK, 2006). Ao diversificar suas fontes de recursos, a universidade é conduzida a não dissociar a "pesquisa básica" da "aplicada". Como salienta Clark (op. cit.), a autonomia financeira da universidade é condição necessária para que ela possa aumentar sua dinâmica e agilidade na competição internacional.

Contudo, mesmo tendo sua autonomia financeira ameaçada, outras instituições conseguem de fato interferir nas autonomias de gestão e de pesquisa da universidade? Como dito por Braun (1998), a comunidade de pesquisa, devido à sua elevada especialização em pesquisa, não permite que aquelas instituições que não estejam familiarizadas com os instrumentos, métodos e regras próprios da atividade científica interfiram nas autonomias da universidade.

Para Cavalli e Teichler (2010), as universidades são consideradas as principais instituições sociais criadas para gerar, preservar e difundir conhecimento sistematizado (pesquisa científica). Há um consenso social de que a comunidade de pesquisa 
é fundamental na atual "sociedade do conhecimento", pois cabe a ela aperfeiçoar os conhecimentos existentes e, com eles, ajudar a melhorar as áreas profissionais.

Além disso, como dito por Bonaccorsi (2010, p. 361), a "nova forma de produção de conhecimento", observada por Gibbons et al. (1994), é tão somente o resultado da dinâmica epistemológica interna à própria ciência. Não é proveniente de pressões sociais externas.

Assim, a inserção das demandas cognitivas da sociedade na pesquisa da universidade é menos resultado de uma preocupação real da comunidade de pesquisa em atendê-las e mais diretamente relacionada a uma forma que ela encontrou para legitimar e, simultaneamente, aumentar suas forças na luta pela manutenção do apoio governamental.

\section{As dimensões de atuação do governo: política da ciência e política para a ciência}

A relação universidade-governo pode ser analisada segundo duas dimensões (ver figura 1). Em uma, a universidade tem suas autonomias de gestão e de pesquisa reduzidas, ou mesmo suprimidas, pelo governo. Nela, prevalece a política da ciência.

Na outra, em que prevalece a política para a ciência, a universidade tem suas autonomias de gestão e de pesquisa preservadas. Mas, a fim de manter o apoio governamental, ela pode estar se valendo de suas autonomias para direcionar sua pesquisa às empresas.

Note que nas duas dimensões não está em questão a autonomia financeira da universidade. Nelas, o governo é o responsável pela alocação dos recursos necessários à pesquisa. Todavia, ao fazer isso ele pode atuar como demandante ou como fomentador da pesquisa.

Na política da ciência, o governo atua como demandante de conhecimento. Nessa dimensão, a universidade está tão ligada ao governo quanto ele a ela. Todavia, este, ao tratá-la como uma de suas extensões, não a desvia de seu verdadeiro fim, que é a "produção de conhecimento desinteressado e, por isso, verdadeiro"?

A resposta poderia ser sim se não fosse o fato de que a própria universidade trata o governo como instrumento para seu progresso. Dessa forma, as autonomias de gestão e de pesquisa que ela reclama para si são meras ilusões (SALOMON, 1974).

Na relação universidade-governo não é proveitoso tentar determinar quem utiliza quem, pois ela é recíproca. O fundamental é entender em que medida os objetivos de um se integram aos do outro (idem, ibid.). 


\section{Figura 1}

As dimensões de atuação do governo

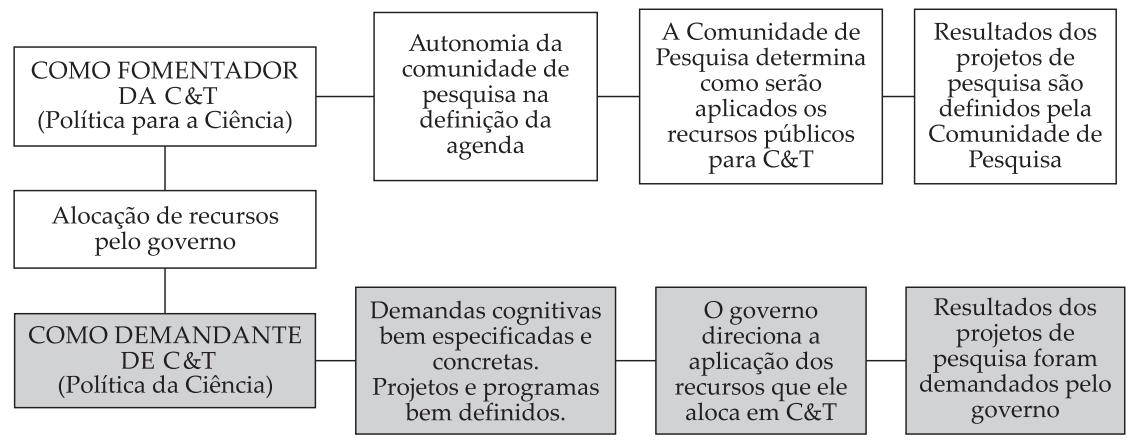

Fonte: Elaboração própria, a partir das proposições de Salomon (1974).

Entre os séculos XVIII e XIX, a universidade aspirava, simultaneamente, ao apoio do governo e a manter-se livre de sua influência. Ela desejava ser vista como o melhor caminho para que ele pudesse lograr seus objetivos. Porém, nessa relação, ela somente oferecia seus préstimos na medida em que pudesse conservar o controle (a autonomia) sobre suas atividades (idem, ibid.).

Todavia, desde a Segunda Guerra Mundial pelo menos não é possível distanciar a universidade dos projetos políticos (policy e politics) implementados pelo governo. Ela pode até ter mantido, em maior ou menor medida, sua autonomia (SALOMON, op. cit.). Contudo, tem passado a depender das decisões políticas que lhe asseguram parte significativa dos recursos necessários ao seu desenvolvimento. Suas autonomias de gestão e de pesquisa estão condicionadas a sua autonomia financeira, ou melhor, aos recursos governamentais.

Desde então, tal como a fronteira entre "pesquisa básica" e "aplicada", deixou de existir (se é que existiu algum dia) uma fronteira entre pesquisa e sua utilização (idem, ibid.).

A pesquisa deixou de estar sob o domínio exclusivo da comunidade de pesquisa. Se a universidade foi incorporada ao governo, isso ocorreu, principalmente, porque ela não pôde prescindir dele para se manter (SALOMON, 1974). A universidade passou a necessitar do apoio político e da alocação de recursos do governo.

Entretanto, o governo ser o responsável pela alocação de recursos na universidade não é um problema, pois a comunidade de pesquisa pode estar desfrutando de "toda a independência que goza o indivíduo em uma sociedade livre" para decidir sobre sua aplicação (SALOMON, op. cit., p. 107). Dessa forma, o governo está atuando como fomentador da pesquisa, prevalecendo a política para a ciência. 
Nessa dimensão, cabe unicamente à comunidade de pesquisa julgar, "com independência", o que deve ser feito para acelerar o "progresso da ciência". Ao governo cabe apenas julgar qual o apoio financeiro merecido por ela.

Como assinalado por Sousa Santos (2005), a autonomia de pesquisa da universidade se assenta na dependência financeira do governo (do Estado). Todavia, essa dependência não implica, como mostra a figura 1, o governo determinar como a universidade deve utilizar os recursos destinados a ela.

Na dimensão política para a ciência, embora ocorra o aporte de recursos públicos, não há uma convergência da pesquisa ao que é declarado como prioritário pelo governo. A pesquisa é orientada pela própria comunidade de pesquisa, de acordo com seus interesses políticos (politics).

Na dimensão política da ciência, a aderência da pesquisa às demandas do governo ocorre em função de arranjos institucionais que levam a um aumento de seu aporte financeiro. Ou seja, nessa dimensão, os recursos governamentais se materializam na universidade como demandas cognitivas bem especificadas e concretas, que se transformam em projetos e programas de pesquisa bem definidos.

\section{A dimensão política da ciência}

Foi necessário menos de meio século para se passar da proposição baconiana - de uma ordem social em que a ciência, planejada e organizada, seria objeto de um desenvolvimento sistêmico - a uma pretensa realidade: em que o "avanço do conhecimento" e a institucionalização da ciência estão ligados oficialmente ao governo (SALOMON, 1974). A "pesquisa básica", fruto da curiosidade do professor-pesquisador, está dando lugar à "pesquisa aplicada", respondendo inclusive às demandas cognitivas do governo.

Isso porque a viabilização da pesquisa produzida pela universidade supõe a existência de recursos financeiros. O governo, por um lado, exige da universidade que ela trate de problemas cuja solução interessa a ele. Por outro, a universidade atende às exigências do governo para, com isso, obter o apoio necessário ao seu desenvolvimento. É estabelecida, dessa forma, uma relação cada vez mais estreita entre governo e universidade. É essa relação que define precisamente a dimensão política da ciência, que remete à existência de laços estreitos e, sobretudo, irreversíveis entre universidade e governo.

A universidade tem chamado a atenção do governo porque ela pode, fundamentalmente, contribuir para a manutenção do poder político dele. Mas, para isso, é necessário fazer com que ela realize tarefas concretas e úteis ao governo. Este passou então a orientar a universidade. Com isso, os professores-pesquisadores 
têm começado a se distanciar das "especulações elevadas" - da prática de uma "pesquisa básica, desinteressada, livre de valores sociais" - para se dedicarem à resolução de problemas práticos.

Quanto mais estreita a relação entre universidade e governo, mais este espera que ela apresente soluções em curto prazo. Dessa forma, a dominação do governo sobre a universidade não é porque ele se interessa pela "pesquisa básica", mas sim pela "pesquisa aplicada", voltada ao atendimento de suas demandas cognitivas (saneamento, moradia, energia, informatização da administração pública, construção de prédios públicos etc.). Esse domínio, para o governo, resulta na aceleração do desenvolvimento econômico, político e social.

Numa sociedade em que a estrutura econômica condiciona a maneira de pensar dos homens, a pesquisa científica é condicionada pelas forças produtivas (SALOMON, op. cit.). Os problemas a que o governo volta sua atenção, e que necessitam de algum esforço da comunidade de pesquisa para sua resolução, são aqueles de âmbito militar, dos transportes, da saúde etc. Aparte os militares, os demais problemas são concebidos, ao mesmo tempo, como passíveis de propiciar o surgimento de novos produtos e como meio de diminuir os entraves do desenvolvimento econômico.

O próprio governo passa a se definir como consumidor e produtor de pesquisa. É ele quem fornece os recursos necessários à sustentação da universidade e quem a incorpora à rede de relações econômicas. Ainda que os bens e serviços prestados pela universidade não se enquadrem precisamente na contabilidade nacional, os recursos com os quais ela se beneficia estão prescritos nas contas públicas.

Quanto mais o governo se interessa pela universidade, mais seletivo ele se torna. Ao alocar recursos na universidade, ele não o faz pensando unicamente na competência da comunidade de pesquisa. Longe de um mecenas desinteressado, o governo está preocupado em integrar a universidade ao sistema econômico. A universidade é concebida como uma força produtiva. Nesse sentido, os esforços da comunidade de pesquisa devem tender, com o máximo de eficácia, ao aumento da riqueza nacional.

A universidade então, devido ao seu enorme custo e ao grande esforço governamental requerido para sua manutenção, se desenvolve somente porque existe uma demanda cognitiva efetiva por parte do governo pela pesquisa produzida por ela.

\section{A dimensão política para a ciência}

Em sociedades democráticas, a autonomia da universidade está assegurada. Na medida em que a democracia se desenvolve, se exclui toda intervenção do governo que não se harmonize com a autonomia da universidade. É essa sentença verdadeira? 
A autonomia da universidade lhe permite estipular os limites à intervenção do governo, seja sobre sua gestão, seja sobre sua pesquisa. Os governantes são suficientemente ilustrados para se darem conta de que não é possível dirigir a universidade e que não conseguem interferir na pesquisa que ela produz. Ao governo cabe somente tirar proveito do progresso do conhecimento, utilizando seus resultados. Isto é o que afirmam os defensores das autonomias de gestão e de pesquisa da universidade.

Nessa perspectiva, o governo deve apenas ser o responsável pelos recursos alocados na universidade. A política da ciência, neste caso, deve ser reduzida à política para a ciência.

Na dimensão política para a ciência, a universidade serve ao governo por meio apenas de suas descobertas. Porém, a função do governo se reduz à de alocar os recursos necessários à consecução da pesquisa da universidade. Isso porque a comunidade de pesquisa, sem o apoio do governo, não pode construir observatórios, criar bibliotecas, fundar grandes estabelecimentos científicos etc. O governo é o responsável por fazer os investimentos necessários à pesquisa.

O governo tem o dever de apoiar a universidade. Porém, daí não se depreende nenhum direito dele sobre ela, pois a pesquisa, assim como a gestão da universidade, pertence ao "império da liberdade" (SALOMON, 1974).

A universidade, por vezes, é assimilada ao governo porque ele é um dos meios com que ela conta para se manter. Todavia, isso não implica sua submissão a ele. $\mathrm{O}$ argumento da utilidade, por mais vazio que possa parecer, é utilizado por ela para persuadi-lo a apoiá-la.

A universidade utiliza o argumento de que sua manutenção contribui para que a sociedade possa alcançar seus anseios. Mesmo que esses anseios sejam identificados em termos de pesquisa para as empresas.

O governo é, por definição, autoridade. E nada parece mais hostil à universidade do que ter que levar em conta uma autoridade que não seja a sua própria. Em nenhum lugar o governo pode impor procedimentos, leis etc. à universidade. Não compete a ele determinar a forma nem o conteúdo da pesquisa da universidade.

O caminho de condução à "verdade" escapa ao governo. Em sentido mais profundo, há uma autoridade da "verdade" - seja científica ou não, porém com maior razão se for - na qual o governo não pode interferir.

De fato, a pretensão do governo em utilizar a universidade para satisfazer suas demandas por pesquisa não implica que isso possa ser correspondido. A orientação de sua pesquisa pelo governo é, por excelência, um mito. 
Os benefícios da pesquisa são tanto maiores quanto mais forem deixadas nas mãos da comunidade de pesquisa as decisões acerca de como orientar e como gerir a universidade, pois cabem a ela as "escolhas racionais".

\section{Política da ciência e política para a ciência e as quatro categorias de relacionamento universidade-governo}

Nas dimensões política da ciência e política para a ciência podem ser observadas ambiguidades. Na política da ciência, o governo, ao alocar recursos na universidade, por um lado, restringe a autonomia dela a fim de conduzi-la a satisfazer suas demandas cognitivas e, por outro, ela é a própria expressão da dominação dele.

Na dimensão política para a ciência, apesar de o governo alocar recursos na universidade, por um lado, ela não é influenciada por ele e conserva suas autonomias de gestão e de pesquisa. Por outro, a fim de manter o apoio político do governo, a universidade conserva sua autonomia por meio de pesquisas tributárias às demandas da empresa.

Essas ambiguidades indicam a existência de quatro categorias de relacionamento, separadas por uma linha tênue, entre universidade e governo. Essas categorias são apresentadas na figura a seguir.

\section{Figura 2}

As quatro categorias de relacionamento entre universidade e governo

Categorias de relacionamento

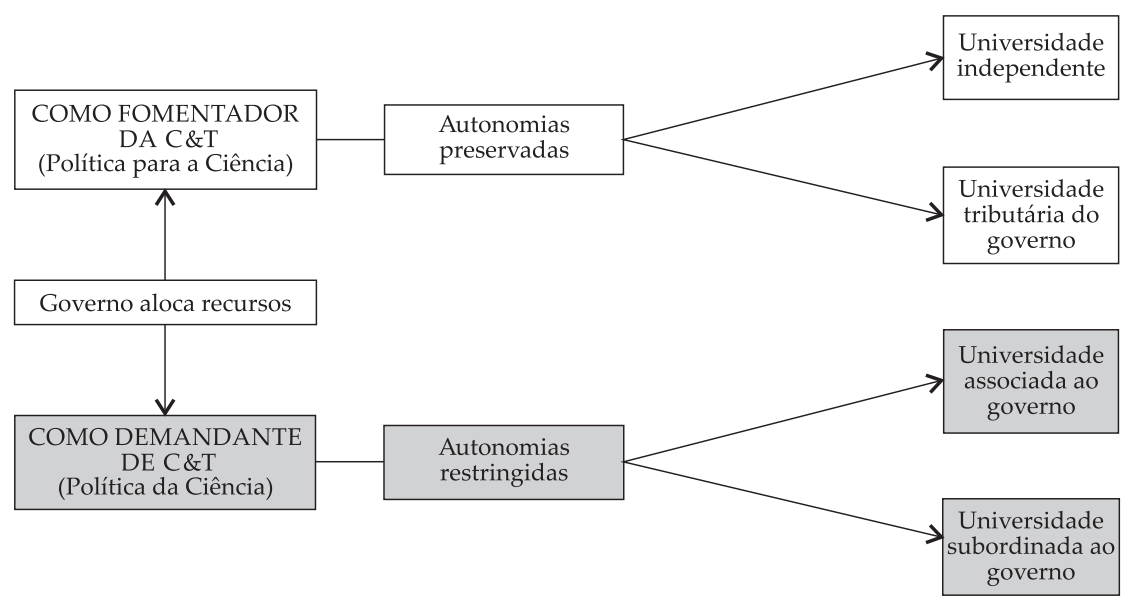

Fonte: Elaboração própria, a partir das proposições de Salomon (1974). 


\section{Política da ciência: a associação entre governo e universidade e a univer- sidade controlada pelo governo}

\section{A universidade associada ao governo}

$\mathrm{Na}$ associação entre universidade e governo, há que se renunciar de saber quem se vale realmente do outro. Não é fácil distinguir o professor-pesquisador do cidadão que luta por alguma causa social. E mais difícil ainda distinguir o que diferencia o apoio prestado pelo governo à universidade e a outras instituições sociais (SALOMON, op. cit.). Isso porque ambos os apoios correspondem a relações políticas (politics).

Na União Soviética e na Alemanha nazista, por exemplo, a universidade se tornou política pelo fato de que o governo era quem definia sua pesquisa e subordinava sua gestão a ele. Foi na União Soviética que se consagrou a relação mais estreita entre universidade e governo. Nela, não só a universidade foi reconhecida como parte do capital nacional, como também integrada às forças produtivas.

Há que se destacar também que o surgimento da atividade acadêmica como profissão, portanto desenvolvida na universidade, esteve ligada à divisão capitalista do trabalho, que estabeleceu uma separação entre trabalho manual e intelectual (entre o planejamento e a execução). Dessa forma, o intelectual tem funções econômicas, sociais e políticas bem determinadas na manutenção e/ou transformação de sociedades concretas (GRAMSCI, 1979).

\section{A universidade subordinada ao governo}

A universidade é um dos instrumentos de dominação do governo. Ao intervir mediante a alocação de recursos destinados à qualificação de profissionais e à infraestrutura universitária, não interessa ao governo a pesquisa por si mesma. Sua atenção está voltada aos benefícios políticos que sua atuação sobre a universidade pode lhe proporcionar.

A universidade é subordinada a projetos modernizadores e autoritários (SOUSA SANTOS, 2005). Ela é obrigada a direcionar suas pesquisas a problemas que levem o governo a se inserir na corrida internacional da inovação tecnológica para que, com isso, ele mantenha sua soberania (seu domínio político e social).

A pesquisa é, dessa forma, subordinada ao sistema social. Mesmo com certa resistência da comunidade de pesquisa, a universidade é instrumentaliza pelo governo a fim de maximizar a riqueza econômica nacional. A pesquisa é voltada, então, para a manutenção da concorrência nacional nos mercados mundiais e à manutenção da coesão social interna (MOURAD, 1997). 


\section{Política para a ciência: a universidade independente e a universidade tributária ao governo}

\section{A universidade independente}

O governo tem o dever de manter financeiramente a universidade. Porém, esse dever não confere a ele nenhum direito de controle ou regulação sobre ela. Inclusive, em certo sentido, o governo tem menos direito sobre a universidade do que sobre as religiões. Nesse caso, vigora o laissez-faire da universidade (SALOMON, 1974).

O pretenso controle do governo sobre a universidade não a impede de se dedicar à pesquisa daqueles problemas eleitos mais em função das escolhas da comunidade de pesquisa do que das do governo.

O governo mantém a universidade porque interessa a ele contribuir para o progresso do conhecimento. Sua ajuda, portanto, não implica nenhum controle sobre ela. Se o governo não apresenta problemas a serem pesquisados é porque este domínio pertence à comunidade de pesquisa.

Os professores-pesquisadores têm obrigação de se comprometer com a "verdade e com a objetividade em suas pesquisas". Universidade e governo não se confundem. A universidade não é instituição política. A sobrevivência da universidade depende de sua capacidade de se manter distante do governo (ALTBACH, 2001).

\section{A universidade tributária do governo}

Depois da Segunda Guerra, começaram a se desenvolver nos EUA pesquisas que aproximaram a universidade dos interesses governamentais. Desde então começou a haver uma convergência dos interesses do governo com os da universidade. O governo passou a aportar recursos na universidade e, em troca, ela começou a direcionar sua pesquisa para o atendimento de demandas cognitivas dele.

Essa transição, todavia, não implicou passar do mundo das autonomias de gestão e de pesquisa ao do controle político. Não foi necessário abandonar o "rio límpido da ciência" para "mergulhar nas águas revoltas da política" (SALOMON, 1974, p. 107). Começou a haver uma mescla entre os dois mundos, cujos critérios e valores, mais ainda que os interesses, estavam até então separados.

A competência da comunidade de pesquisa, fundada na "busca desinteressada pela verdade objetiva a respeito do mundo natural" (frase atribuída a Richard Dawkins), se associou aos conflitos e aos embates da convicção política. O governo não abandonou a universidade a sua própria sorte. Coube a ele acelerar o ritmo da pesquisa científica e tentar colocá-la ao serviço de seus interesses. 
Se o governo não pode dizer à comunidade de pesquisa como ela deve orientar suas pesquisas e, menos ainda, o que deve descobrir, então ele pode pelo menos indicar aqueles problemas que são de seu interesse.

Nesse processo, uma nova linguagem foi "inventada": a da aplicação, contextualização, transferência de tecnologia e gerenciamento (NOWOTNY;SCOTT; GIBBONS, 2003).

Todavia, com isso, a universidade pode estar servindo ao governo para libertar-se da influência dele. Pode estar tirando partido das garantias de autonomia que o governo lhe dá (BOURDIEU, 2004).

\section{Considerações finais}

De um lado, sem que isso implique uma postura dicotômica, a sociedade deseja uma universidade menos autônoma, não somente sob o ponto de vista de sua gestão, mas, principalmente, de sua pesquisa. Uma universidade voltada às demandas cognitivas sociais.

De outro lado, há uma parcela da comunidade de pesquisa que luta para conservar as autonomias da universidade e para que o governo continue fomentando suas pesquisas, e outra que vislumbra na pressão social a possibilidade da universidade conseguir sua autonomia financeira e, com ela, uma "verdadeira" autonomia de gestão e de pesquisa. Neste caso, autonomia em relação ao governo.

Mais do que uma coisa ou outra, as quatro categorias de relacionamento aqui apresentadas mostram que a universidade, longe de responder a uma concepção única sobre a organização de sua pesquisa e de sua gestão, é formada desde relações de poder existentes em cada momento histórico.

Apesar dessa relação controvertida entre governo e universidade, um ponto comum permite que ambos estejam sempre associados: são instituições sociais que, apesar de sua liberdade relativa, são fundamentais ao modo de produção capitalista.

Essa percepção permite uma resposta diferente à dada por Clark (2006) ao dizer que a universidade foi pressionada a se tornar autônoma financeiramente por não ter conseguido dar conta das demandas cognitivas sociais (em especial, a da empresa).

Na realidade, a observação de Clark pode ser reformulada da seguinte forma: a universidade não vem conseguindo atender às demandas cognitivas econômicas na velocidade desejada pela sociedade (particularmente pela empresa), uma vez que 
sua pesquisa permaneceu voltada à produção de bens e mercadorias, algo que foi requisitado até o fim dos anos de 1960 e início dos de 1970.

Até esses anos, o capitalismo vivia um momento caracterizado por um regime internacional relativamente estável, em que seus sustentáculos eram o sistema de paridades fixas entre as moedas e o modelo fordista de produção associado ao consumo de massa (CHESNAIS, 1996).

No entanto, entre 1978 e 1979, no momento do segundo choque do petróleo, a combinação de vários fatores tornaram frágeis esses sustentáculos. Nesse momento, houve uma saturação da procura por bens de consumo duráveis. Diante disso, as grandes firmas procuraram saídas para a queda da rentabilidade do capital (idem, ibid.).

Por conta dessa crise, caracterizada pela "destruição" de formas institucionais essenciais, passa a ocorrer de forma mais intensiva a internacionalização do capital. Os governos e as elites dos principais países avançados deixaram o capital financeiro tornar-se uma força, praticamente incontrolável, no âmbito mundial (idem, ibid.).

A pesquisa da universidade, que nas décadas de 1960 e 1970 já estava adaptada ao capital produtivo - portanto voltada à oferta de bens e mercadorias -, já em meados dessa última década também começou a ser questionada mais veementemente pela sociedade.

Foi a essa mudança do capitalismo que a universidade não conseguiu dar resposta na mesma velocidade de integração dos mercados mundiais. E como a universidade se constitui num pilar fundamental dessa estrutura social, ela rapidamente foi pressionada a entrar nessa fase de reprodução do capital.

Na atual fase da produção capitalista - de mundialização do capital e de predominância financeira, de transformação da ciência em mercadoria essencial ao aumento da mais-valia relativa e de reformas funcionais do aparelho do Estado para garantir o "bom" funcionamento do capital com os recursos do fundo público e com legislação pertinente - a universidade está deixando de ser uma instituição relativamente autônoma para tornar-se cada vez mais uma organização a serviço do mercado (da empresa).

\section{Referências}

ALTBACH, P. Academic freedom: international realities and challenges. Higher Education, Amsterdam, n. 41, p. 205-219, 2001. 
BONACCORSI, A. New forms of complementarity in science. Minerva, Amsterdam, n. 48, p. $355-387,2010$.

BOURDIEU, P. El oficio de científico. Barcelona: Anagrama, 2003.

BOURDIEU, P. Os usos sociais da ciência. São Paulo: Unesp, 2004.

BRAUN, D. The role of funding agencies in the cognitive development of science. Research Policy, Amsterdam, v. 27, n. 18, p. 807-821, 1998.

CAVALLI, A.; TEICHLER, U. The academic profession: a common core, a diversified group or an outdated idea? European Review, v.18, n. S1, p. S1-S5, 2010.

CHESNAIS, F. A mundialização do capital. São Paulo: Xamã, 1996.

CIMOLI, M. et al. Instituições e políticas moldando o desenvolvimento industrial: uma nota introdutória. Revista Brasileira de Inovação, Campinas, v. 6, n. 1, p. 55-85, 2007.

CLARK, B. Em busca da universidade empreendedora. In: AUDY, J.; MOROSINI, M. (Org.). Inovação e empreendedorismo na universidade. Porto Alegre: Edipucrs, 2006. p. 15-41.

DIAS, R. A política científica e tecnológica latino-americana: relações entre enfoques teóricos e projetos políticos. 2005. Dissertação (Mestrado em Política Científica e Tecnológica) - Instituto de Geociências, Universidade Estadual de Campinas, Campinas.

ETZKOWITZ, H. The triple helix of university - industry - government: implications for policy and evaluation. Sister, Estocolmo, 2002.

GIBBONS, M. et al. La nueva producción del conocimiento: la dinámica de la ciencia y la investigación en las sociedades contemporáneas. Barcelona: Pomares-Corredor, 1994.

GRAMSCI, A. Os intelectuais e a organização da cultura. Rio de Janeiro: Civilização Brasileira, 1979.

KOURGANOFF, W. A face oculta da universidade. São Paulo: Unesp, 1990.

MARX, K.; ENGELS, F. A ideologia alemã. São Paulo: Martins Fontes, 1989.

MOURAD, R. Postmodern philosophical critique and the pursuit of knowledge in higher education. Washington, DC: Library of Congress, 1997.

NOWOTNY, H.; SCOTT, P.; GIBBONS, M. "Mode 2" revisited: the new production of knowledge. Minerva, Amsterdam, v. 41, p. 179-194, 2003. 
O'DONNELL, G. Anotações para uma teoria do Estado. Revista de Cultura e Política, Rio de Janeiro, n. 3, p. 71-82, 1981.

RUIZ, A. Patentes y función publica universitaria en Europa: mitos y realidades. Revista Brasileira de Inovação, Campinas, v. 4, n. 2, p. 391-423, 2005.

SALOMON, J.J. Ciencia y política. México, DF: Siglo XXI, 1974.

SCHWARTZMAN, S. Higher education in Brazil: the stakeholders. Washington, DC: World Bank, 1998. (Papers series n. 28).

SOUSA SANTOS, B. A universidade no século XXI: para uma reforma democrática e emancipatória da universidade. Educação, Sociedade e Culturas, Porto, n. 23, 2005.

Recebido em 19 de abril de 2011.

Aprovado em 14 de dezembro de 2012. 